\title{
Understanding the Healthy Immigrant Effect in the Context of Mental Health Challenges: A Systematic Critical Review
}

\author{
Sarah Elshahat ${ }^{1}$ (1) $\cdot$ Tina $_{\text {Moffat }}{ }^{1} \cdot$ K. Bruce Newbold ${ }^{2}$ \\ Accepted: 1 November 2021 / Published online: 22 November 2021 \\ (c) The Author(s), under exclusive licence to Springer Science+Business Media, LLC, part of Springer Nature 2021
}

\begin{abstract}
The "Healthy Immigrant Effect" (HIE) suggests that immigrants have a health advantage over the domestic-born which vanishes with increased length of residency. Most HIE research focuses on physical health, with less attention given to mental health $(\mathrm{MH})$. This systematic review of $58 \mathrm{MH}$ studies examines whether there is a $\mathrm{MH}$ advantage among immigrants and explores changes in immigrants' MH, besides critically assessing the use of HIE theory. Inconsistent evidence was detected regarding the presence of $\mathrm{MH}$ advantage, whereas consistent, convincing evidence was revealed for a decline in immigrants' MH over years. Although the HIE theory can help reveal MH disparities, this theory alone does not explain the reasons for these disparities nor inform about potential avenues to improve immigrants' MH. A paradigm shift is needed to incorporate other potential theoretical concepts/frameworks, including the "Health Inequalities Action" framework, for a broader understanding of MH issues and to inform effective, culturally-sensitive interventions.
\end{abstract}

Keywords Healthy immigrant effect $\cdot$ Years since immigration effect $\cdot$ Immigrants $\cdot$ Mental health $\cdot$ Depression $\cdot$ Anxiety

\section{Introduction}

\section{Background}

There has been a growing worldwide emphasis on addressing mental health (MH) needs as a global public health priority within the United Nations Sustainable Development Agenda, with the third goal that focuses on promoting healthy lives and mental well-being for all populations $[1,2]$. Mental health challenges affect over $15 \%$ of the population worldwide, leading to subsequent physical health problems/ disabilities as well as health and social disparities. In highincome countries, the prevalence of $\mathrm{MH}$ issues is highest in the US, Canada, and Australia (about 20\% each), followed by Europe (nearly 17\%) [3]. Immigrants are particularly at increased risk for $\mathrm{MH}$ challenges as a result of various socio-economic, cultural and ecological factors [4]. These include, but are not limited to, difficulties accessing health

Sarah Elshahat

elshahas@mcmaster.ca

1 Faculty of Social Sciences, McMaster University, CNH 527, Hamilton, ON L8S 4L9, Canada

2 School of Earth, Environment \& Society, McMaster University, Hamilton, ON L8S 4K1, Canada and social care services, racism, social exclusion as well as unequal employment conditions and opportunities. A thorough understanding of $\mathrm{MH}$ challenges among international immigrants (i.e., individuals living in a country other than their country of origin) is critically needed in countries where international migration is a key driver of population growth and economic prosperity. Over the last two decades, there has been an approximately $60 \%$ increase in the number of international immigrants worldwide [5, 6]. In Western countries, Australia and Canada constitute the highest proportions of foreign-born immigrants (30 and 22\%, respectively) $[7,8]$. These are followed by the US and Europe, where immigrants represent about 16 and $14 \%$, respectively, of the total populations in these nations [9].

\section{Theoretical Frameworks and Concepts}

\section{Healthy Immigrant Effect and Resilience}

Within immigrant health research, there has been a focus on the "healthy immigrant effect" (HIE) theory, also called the "Immigrant Paradox", which suggests that immigrants exhibit better health outcomes than domestic-born populations in the destination country [10]. Most of the research that supports the presence of health advantage 
among immigrants focuses on mortality, overall health and physical health outcomes/indicators (e.g., body mass index, total cholesterol, diabetes), demonstrating lower prevalence of these diseases/indicators for immigrants compared to host populations when potential confounders are controlled for in the models [11-13]. Little specific attention, on the other hand, has been given to MH outcomes in HIE studies [14]. Across studies that employed the HIE theory for investigating immigrants' health, there is inconsistency in the definition of both immigrant and domestic-born/reference groups [15]. While some studies define immigrants as solely those who are foreign-born (1st generation immigrants) [16, 17], others have a much broader definition, including foreign-born immigrants and their domestic-born descendants (2nd and/or 3rd + generation immigrants) $[18,19]$. Regarding comparison groups, studies show substantial variations, where definitions varied between $2 \mathrm{nd}+/ 3 \mathrm{rd}+$ generation immigrants, domestic-born non-immigrants, or a combination of both [17, 20,21]. These inconsistencies in definitions highlight the need for caution when interpreting HIE studies' findings with regards to the presence of health advantage among immigrants.

The health advantage observed among immigrants has often been linked to "the immigrant selection hypothesis" that suggests a positive selection of healthy immigrants into the receiving country at individual and national levels [12]. Regarding the individual level, immigrants are suggested to be a self-selected segment of the population of the country of origin, with better health and social outcomes relative to non-immigrants in the sending country [12, 22]. At the national level, the positive selection process occurs through strict migration policies, such as points-based systems in the immigrant-seeking countries (e.g. Canada and Australia), that favor/screen for healthy, well-educated immigrants [23]. These perspectives, however, fail to take into consideration refugees and undocumented immigrants' situations, which often do not involve a positive self-selection at either the individual or national level. Previous HIE research has also attributed the observed health advantage among immigrants to their resilience, suggesting that newcomers, particularly those who are positively selected, have the motivation and determination to succeed, effectively navigating the destination country's key resources and community assets that help sustain their overall health and well-being [24, 25]. Resilience is suggested to be a dynamic process that encompasses continuous positive adaptation against adverse life events $[26,27]$. A broader definition for resilience includes the structural and wider community protective factors and processes/mechanisms that contribute to favourable outcomes despite continuing stressors that place communities and individuals' mental health and psychological well-being at risk [28, 29].

\section{Years Since Immigration Effect, Acculturation and Cumulative Stress Theories and Social Suffering}

A complementary phenomenon to the HIE theory is the "years since immigration effect" (YSIE), which proposes that the initially healthy immigrants experience a decline in their health outcomes with increased length of residency in the destination country [30]. There is limited attention given to the YSIE in HIE research, with most studies that assessed the phenomenon adopting a cross-sectional or secondary analysis design [12,31]. A longitudinal design is the most efficient methodology to examine the YSIE phenomenon, allowing for a reliable assessment of the long-term change in immigrants' health through excluding unobserved individual differences and time-invariants [32-34]. The observed decline in immigrants' health over time has been linked to unhealthful acculturation into a Western lifestyle (i.e., giving up one's ethnic identity and associated healthy practices and adopting risky/unhealthy behaviors, including over-reliance on low-nutrient, convenience food and sedentary lifestyle, etc.). Another common explanation for the noted decline in immigrants' health is related to the cumulative exposure to various stressors at different levels: individual (e.g. financial constraints, language issues), societal (e.g. discrimination, racism, unequal job opportunities) and organizational (e.g. difficulties navigating food, housing, health and social care systems) [35]. These stressors are suggested to build up gradually over years, eventually giving rise to the noted decline in their health with increased length of residency [36]. This aligns with the cumulative stress theory and suggests that human exposure to different stressors cumulatively adds up to cause a dysregulation of physiological mediators, resulting in various physical and $\mathrm{MH}$ impairments [37].

Despite the socio-cultural and structural nature of the problem, there has been a notable increase in the medicalization of MH challenges that is often driven by pharmaceutical industry's interest in the creation of broader diagnostic categories and markets for "selling sickness", underrecognizing individuals' lived negative experiences and social suffering. The term "social suffering" was coined by Kleinman [38] to demonstrate that most dayto-day social life involves suffering and pain that can be normative and normal. Social suffering could also refer to various abnormal human experiences from individual catastrophes-related social consequences to collective disasters. Indeed, many cases of anxiety and depression in our contemporary societies can be a form or a result of social suffering [39]. For example, Anglin et al. [40] note that aggressive policing practices (e.g. stop and frisk) and arrest history are associated with poor MH outcomes among African Americans. 


\section{Previous Research and the Current Study}

Previous reviews that employed the HIE theory mainly focused on either overall health or physical health outcomes among immigrants [12, 13, 41]. Findings of these studies may not be applicable to immigrants' MH outcomes. Although most HIE-physical health research found a health advantage among immigrants, this advantage may not translate to immigrants' MH. For example, positively health selected immigrants may develop symptoms of psychological distress as a result of the stressful migration processes (e.g. long waiting for decision on immigration application, visa issues), arriving in the destination country with newly developed MH challenges [42, 43]. Islam [44] conducted a HIE literature review to examine immigrants' $\mathrm{MH}$ in Canada and reported inconclusive evidence regarding the presence of MH advantage among immigrants. The review, however, did not employ a systematic search strategy nor did it develop clear eligibility criteria based on which the included articles were selected. Furthermore, Islam [44] did not adopt a clear evidence synthesis approach to robustly synthesize the existing evidence.

Employing the HIE theory, this systematic review aims to robustly and comprehensively examine $\mathrm{MH}$ outcomes among immigrants in Western countries (Canada, the US, Europe, Australia and New Zealand) and to assess the applicability of the HIE theory to immigrants' MH status across separate MH diagnoses. This will help direct future HIE-MH research and inform $\mathrm{MH}$ practices in immigrant-receiving countries. The objectives of this study are: (1) examine the presence of $\mathrm{MH}$ advantage among immigrants compared to domestic-born individuals, (2) explore whether there is a decline or increase in immigrants' $\mathrm{MH}$ with increased length of residency in the destination country, and 3) critically assess the use of the HIE theory in MH studies of immigrants. This is the first HIE-guided systematic review to critically examine immigrants' $\mathrm{MH}$.

\section{Methods}

A systematic review was conducted adhering to PRISMA guidelines to address the review's objectives effectively [45]. A retrospective registration of this review was made in the International Prospective Register of Systematic Reviews (PROSPERO).

\section{Search Strategy}

Sixty-one search terms, including generalized ones, that reflect the main concepts of this review (mental health and HIE/Immigrant Paradox) were employed and combined utilizing Boolean operators OR/AND (Online Appendix
Table S1). Five automated databases were searched from inception to January 2021: PubMed, Medline, Embase, PsycINFO and Sociology Database. The research was restricted to human studies published in the English language. A manual search of the bibliography of potentially pertinent articles was also carried out.

\section{Study Selection}

Articles were only considered for inclusion if they employed the HIE theory to investigate $\mathrm{MH}$ among international immigrants/refugees. There was no restriction on immigrants' country of origin. To strike a balance between minimizing heterogeneity while being comprehensive, only research carried out in Western countries (North America (Canada and the US), Europe, Australia and New Zealand) was included. All MH conditions and proxy MH indicators (e.g., life satisfaction) across all age/ gender groups were included. All research designs, except for any types of reviews, were eligible. Papers utilizing the HIE theory to only explore physical health of immigrants were excluded. Studies examining the effectiveness of $\mathrm{MH}$ therapies/interventions among immigrants were also not eligible. These eligibility criteria were employed to screen the titles and abstracts of the retrieved papers after duplicate removal. All potentially pertinent articles were then carefully examined in full (Fig. 1).

\section{Data Extraction}

A pre-established data collection tool was used to extract pertinent data. This involved authorship, study design, $\mathrm{MH}$ variables, participants' characteristics, destination country and the major findings. To help answer the review's questions in an efficient manner, data were separately classified according to whether they addressed the presence of $\mathrm{MH}$ advantage among immigrants compared to the domestic-born (i.e., HIE) and/or the change in immigrants' MH patterns over years (i.e., YSIE). Data were mainly extracted for 1st generation immigrants (i.e., foreign-born immigrants) to aid comparability. Since there is inconsistency in definition of domestic-born populations in the HIE literature, data were extracted for any Western countries' domestic-born individuals as comparators. To address the review's objective regarding the presence of the YSIE, data were extracted for recent 1 st generation immigrants as the population to investigate, whereas established 1st generation immigrants were comparators. Since there is no standard definition for recent and established immigrants in the HIE literature, any definitions by the authors of the included studies were deemed eligible. 
Fig. 1 Flow diagram presenting the included studies

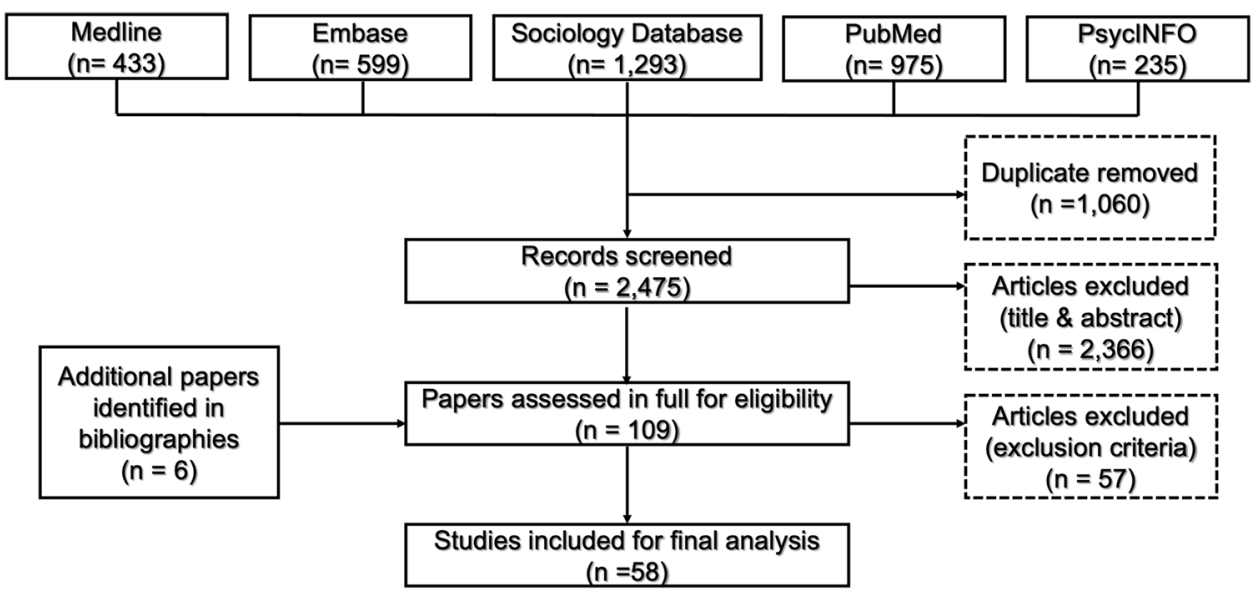

\section{Assessing Quality and Synthesizing Evidence}

An eight-element checklist was especially developed for quality appraisal of the included articles through adaptation from the Center for Evidence-Based Management recommendations and previous relevant research (Table 1) [15, 46-48]. These eight elements included: [1] research design (weight: longitudinal quantitative $=2$, cross-sectional or secondary analysis $=1$, any qualitative $=0.5$ ), [2] response rate (reported $\geq 75 \%=1$, not reported or reported $<75 \%=0$ ), [3] adjusting for socio-demographic confounders (yes $=1$, no $=0$ ), [4] method of $\mathrm{MH}$ measurement (objective $=1$, subjective $=0.5$ ), [5] Examination of the HIE and YSIE phenomena (both phenomena examined $=1$, only one phenomenon examined $=0.5$, neither phenomenon examined $=0$ ), [6] Clear definition of immigrants group (yes $=1$, no $=0$ ), [7] Clear definition of comparison group (yes $=1, \mathrm{no}=0$ ), and [8] Examination of variations in $\mathrm{MH}$ across ethnicities (yes $=1$, no $=0$ ). Higher scorings demonstrate better quality: $\leq 4$ (low quality), 4.1-5.9 (medium quality) and $\geq 6$ (high quality). In accordance with previous systematic reviews that produced objective conclusions based upon statistical theory [48-50], a threshold of $\geq 60 \%$ of significant evidence for the presence of HIE (revealed in a minimum of four studies) was utilized to define consistent, convincing evidence of existence of MH advantage among immigrants (Table 2). The same approach was employed to draw objective conclusions on the presence of the YSIE for each MH diagnosis (Table 3). To make a comprehensive critical assessment of the use of HIE theory in immigrant MH studies, data were categorized into three groups: conceptual and usage issues, study design issues, and measurement and analysis issues.

\section{Results}

\section{Characteristics and Quality of the Eligible Studies}

The automated database search yielded 3535 records, in addition to six potential papers identified through the bibliographies of pertinent articles (Fig. 1). Of these, only 58 papers met the eligibility criteria. Half of the studies were conducted in the US, whereas Canada was the second most common country of study origin (26\%), followed by Europe (21\%) (Online Appendix Table S2). Approximately 90\% of the studies adopted either a cross-sectional or a secondary analysis (of cross-sectional data) design. Over two-thirds (69\%) of the studies recruited mixed migrants from different regions of the world. Latin America was the most common region of origin (21\%), followed by Asia (9\%). Around half of the studies were deemed of moderate quality, and about $34 \%$ were of high quality. Adjustment for socio-demographic confounders was carried out in $88 \%$ of the studies. Only $21 \%$ of the eligible papers showed a reliable response rate ( $\geq 75 \%$ ) [51]. Examination of both the HIE theory and the YSEI phenomenon was considered in only $40 \%$ of the included studies (Online Appendix Table S2). Overall MH was investigated in about a third of the included studies. Depression was the most examined MH condition (43\%), followed by anxiety (29\%).

\section{Presence or Absence of Mental Health Advantage?}

Forty-nine studies exploring the presence of MH advantage among immigrants were included. These were categorized into two subsections according to the $\mathrm{MH}$ outcomes 


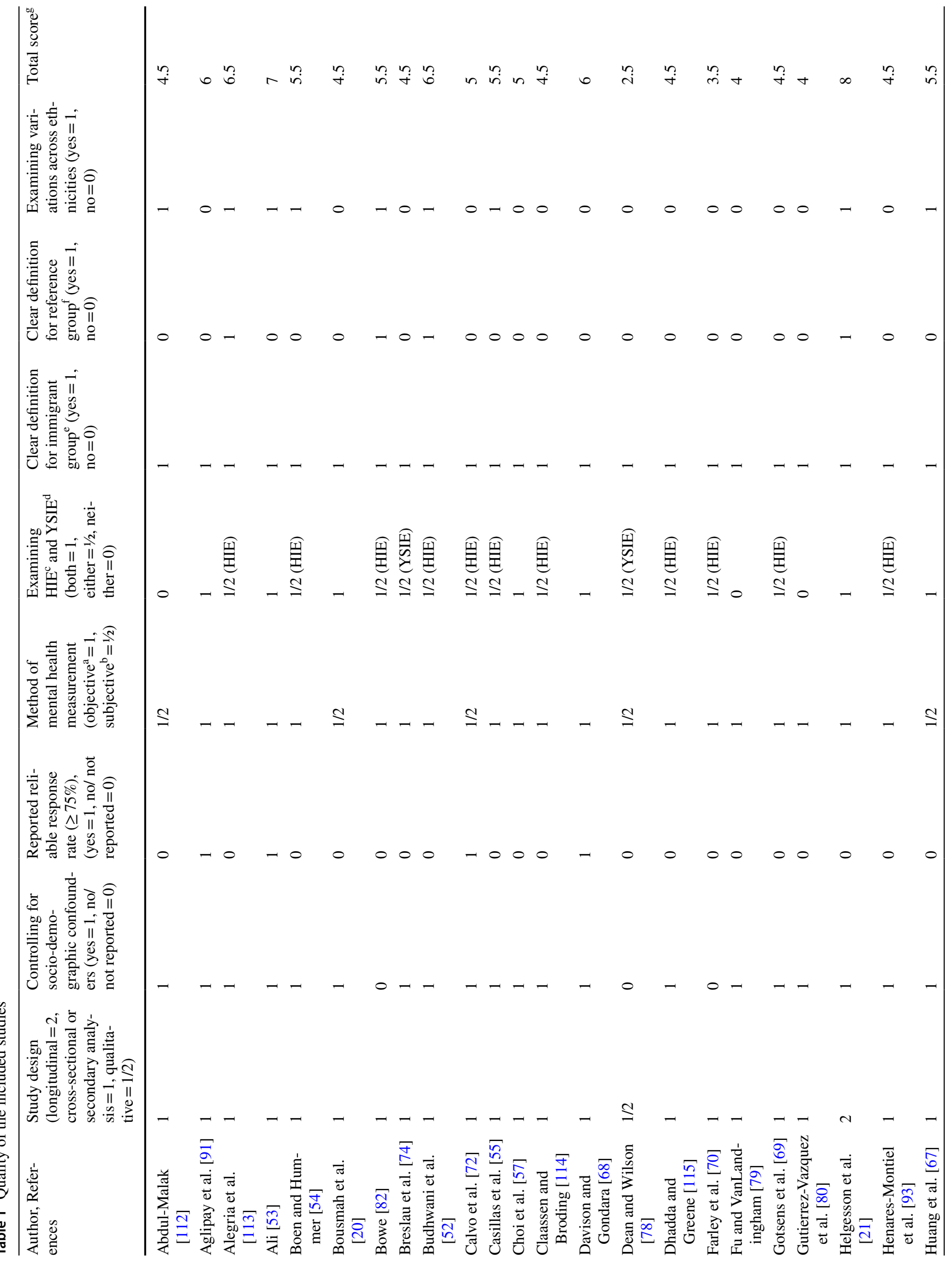




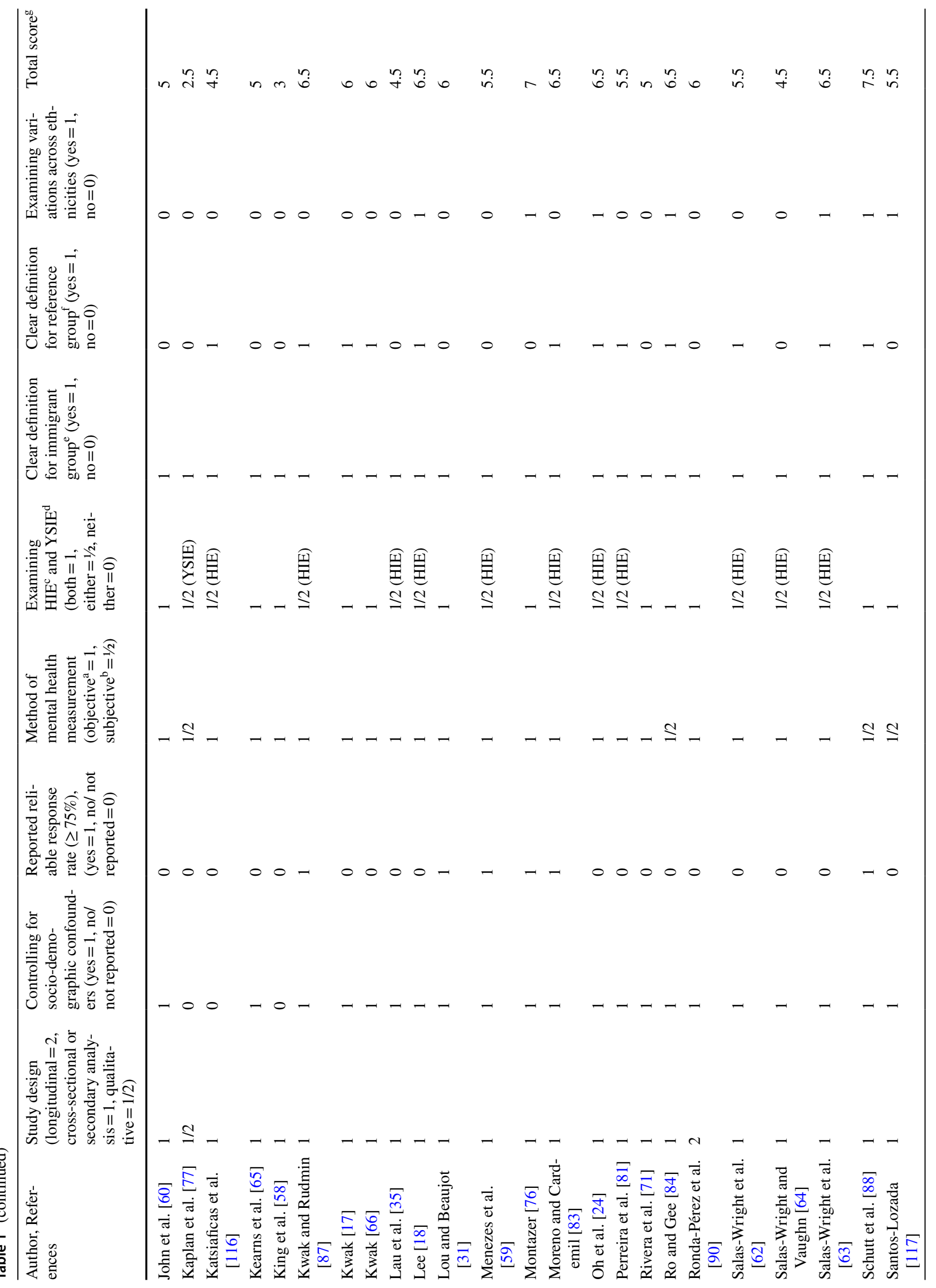




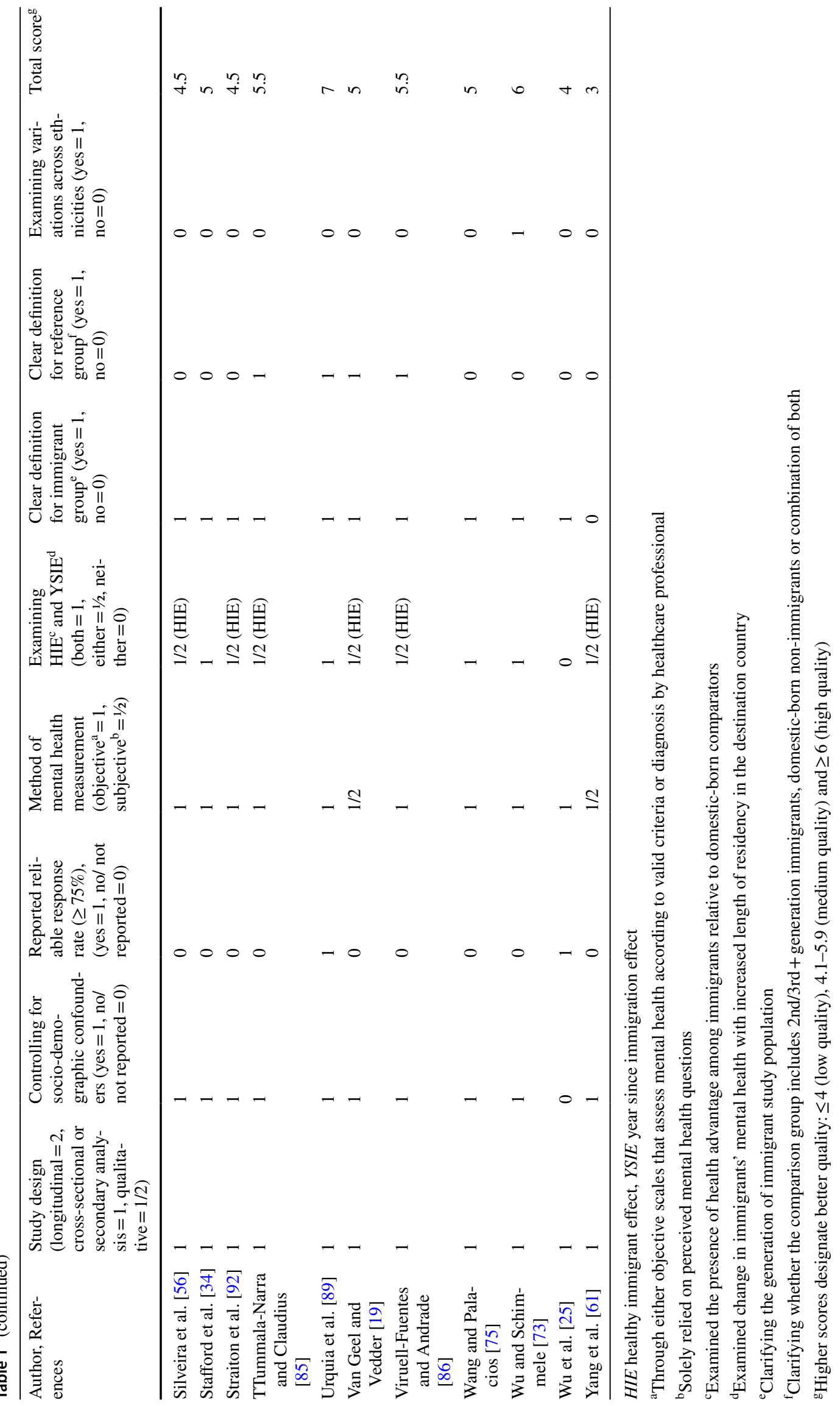


Table 2 Examination of the presence of mental health advantage among immigrants compared to domestic-born individuals

\begin{tabular}{|c|c|c|c|c|c|}
\hline Mental health issue/measure & $\begin{array}{l}\text { Significant better mental health } \\
\text { outcomes }^{\text {a }}\end{array}$ & $\begin{array}{l}\text { Significant worse } \\
\text { mental health } \\
\text { outcomes }^{\text {b }}\end{array}$ & Non-significant & $\begin{array}{l}\% \text { studies that } \\
\text { support the } \\
\mathrm{HIE}^{\mathrm{c}}\end{array}$ & $\begin{array}{l}\text { Sum- } \\
\text { mary } \\
\text { codes }\end{array}$ \\
\hline Depression & $\begin{array}{l}{[34,35,52,53,61,73,83,85,86,} \\
\quad 113]\end{array}$ & {$[55,56,89,92]$} & {$\left[57,58,60,81^{\mathrm{d}}\right]$} & $55 \%$ & $? ?$ \\
\hline Anxiety & {$\left[35,59,60,62,91^{\mathrm{e}}, 113\right]$} & & {$\left[55,58,61,81^{d}, 83,91^{f}\right]$} & $50 \%$ & $? ?$ \\
\hline Psychological distress & [76] & {$[57,114]$} & & $33 \%$ & 0 \\
\hline Mood disorder & {$[59,62]$} & & & $100 \%$ & + \\
\hline Personality disorders & {$[62]$} & & & $100 \%$ & + \\
\hline Psychosis & {$[59]$} & & {$[24]$} & $50 \%$ & $?$ \\
\hline Substance use disorder & {$[59,63,64]$} & & [83] & $75 \%$ & + \\
\hline Depression or anxiety & {$[82,88]$} & [116] & & $67 \%$ & + \\
\hline Anxiety or mood disorder & {$[17,66,87]$} & & & $100 \%$ & + \\
\hline Overall mental health & {$[19,31,65-67,84,90,93,117]$} & {$\left[18^{\mathrm{d}}, 21,68,69^{\mathrm{g}}\right]$} & {$\left[20,57,60,69^{\mathrm{h}}, 70\right]$} & $50 \%$ & $? ?$ \\
\hline Well-being & {$[65,71]$} & & & $100 \%$ & + \\
\hline Life satisfaction & {$[72]$} & & & $100 \%$ & + \\
\hline
\end{tabular}

HIE healthy immigrant effect

${ }^{\text {a } I n v o l v e s ~ e i t h e r ~ l o w ~ m e n t a l ~ h e a l t h ~ p a t h o l o g i e s ~ o r ~ o p t i m a l ~ o v e r a l l ~ m e n t a l ~ h e a l t h, ~ w e l l-b e i n g ~ a n d ~ l i f e ~ s a t i s f a c t i o n ~}$

${ }^{\mathrm{b}}$ Involves either high mental health pathologies or poor overall mental health, well-being and life satisfaction

${ }^{\mathrm{c}}$ Number of studies supporting the predicted HIE theory divided by the whole number of studies examined each mental health outcome. $+=$ evidence for presence of mental health advantage (60-100\% of papers supporting the predicted HIE theory); $0=$ no evidence for presence of mental health advantage $(0-33 \%$ of papers supporting the predicted HIE theory); ?=inconsistent evidence for presence of mental health advantage (34-59\% of papers supporting the predicted HIE theory); Single signed codes $(+, 0, ?)$ were given when a significance evidence for presence of mental health advantage was found in less than four studies; Double signed summary coding $(++, 00, ? ?)$ indicates that a significance evidence for presence of mental health advantage was revealed in four or more studies

${ }^{\mathrm{d}}$ Immigrant group included combined 1st and 2nd generation immigrants

${ }^{\text {e}}$ Participants ageing $<60$ years

${ }^{\mathrm{f}}$ Participants ageing $\geq 60$ years

${ }^{\mathrm{g}}$ Females

${ }^{\mathrm{h}}$ Males

Table 3 Examination of the presence of the YSIE across different mental health issues/measures

\begin{tabular}{|c|c|c|c|c|c|}
\hline Mental health issue/measure & Significant deterioration $^{\mathrm{a}}$ & $\begin{array}{l}\text { Significant } \\
\text { improvement }^{b}\end{array}$ & Non-significant change & $\begin{array}{l}\% \text { studies that sup- } \\
\text { port the YSIE }\end{array}$ & $\overline{\text { Summary codes }}$ \\
\hline Depression & {$[73]$} & & {$[57,58,60]$} & $25 \%$ & 0 \\
\hline Anxiety & [74] & & {$[58,60]$} & $33 \%$ & 0 \\
\hline Psychological distress & {$[75]$} & {$[57]$} & {$[76]$} & $33 \%$ & 0 \\
\hline Mood disorder & & & {$[74]$} & $0 \%$ & 0 \\
\hline Anxiety or mood disorder & [17] & & {$[66]$} & $50 \%$ & $?$ \\
\hline Either depression or anxiety & {$[88]$} & & & $100 \%$ & + \\
\hline Overall mental health & {$[20,31,65-67,84,90]$} & {$[68]$} & {$[57,60]$} & $70 \%$ & ++ \\
\hline Well-being & {$[65,71]$} & & & $100 \%$ & + \\
\hline
\end{tabular}

YSIE years since immigration effect

${ }^{a}$ Involves either increase in mental health pathologies or decrease in overall mental health and well-being over years

${ }^{\mathrm{b}}$ Involves either reduction in mental health pathologies or improvement in general mental health and well-being over years

${ }^{\mathrm{c}}$ Number of studies supporting the predicted YSEI phenomenon divided by the whole number of studies examined each mental health outcome. $+=$ evidence for presence of YSIE for the investigated mental health outcome $(60-100 \%$ of papers supporting the predicted YSIE phenomenon); $0=$ no evidence for presence of YSIE (0-33\% of papers supporting the predicted YSIE phenomenon); ?=inconsistent evidence for presence of YSIE (34-59\% of papers supporting the predicted YSIE phenomenon); Single signed codes $(+, 0, ?)$ were given when a significance evidence for presence of YSIE was found in less than four studies; Double signed summary coding $(++, 00, ? ?)$ indicates that a significance evidence for presence of YSIE was revealed in four or more studies 
investigated: $\mathrm{MH}$ pathologies and overall $\mathrm{MH} /$ proxy indicators.

\section{Mental Health Pathologies}

Studies showed inconsistent evidence for the presence of $\mathrm{MH}$ advantage among immigrants in terms of lower depression, anxiety and psychosis compared to domestic-born populations (Table 2). While some studies revealed significantly lower depression scores among 1st generation immigrants relative to domestic-born individuals [34, 52, 53], others showed significantly higher depression levels [54-56]. Still, other studies do not reveal any significant differences [57, 58]. Anxiety and psychosis scores were significantly lower amongst 1st generation immigrants compared to the host population in North America in studies by Menezes et al. [59], John et al. [60] and Lau et al. [35] whereas other studies did not detect any significant differences [24, 58, 61]. Studies revealed no significant evidence for the presence of health advantage among immigrants in terms of lower psychological distress levels relative to domestic-born individuals (Table 2). Two North American studies, on the other hand, exhibited that 1 st generation immigrants have significantly lower mood and personality disorders than domesticborns [59, 62]. Likewise, 1st generation immigrants/refugees in North America showed significantly lower substance use disorders than domestic-born comparators [59, 63, 64].

\section{Overall MH and Proxy Indicators}

No consistent evidence was revealed for more optimal overall MH among immigrants, compared to domestic-born individuals (Table 2). Immigrants in North America and Europe showed significantly better overall MH compared to domestic-borns in studies by Kearns et al. [65], Kwak [66], and Huang et al. [67] whereas other North American and European studies either revealed significantly worse overall MH [68, 69] or non-significant differences [20, 60, 70]. Well-being was investigated in only two European studies and was significantly higher among 1 st generation immigrants relative to domestic-born individuals [65, 71]. Calvo et al. [72] reported significantly higher life satisfaction levels among immigrants compared to US-born individuals.

\section{Change in Immigrants' MH with Increased Length of Residency}

Eighteen studies examining the change in $\mathrm{MH}$ of immigrants over years were included. These were classified into two subsections according to the $\mathrm{MH}$ outcomes assessed: $\mathrm{MH}$ pathologies and overall $\mathrm{MH} /$ proxy indicators.

\section{Mental Health Pathologies}

Studies showed no significant evidence for an increase in either depression or anxiety levels among immigrants with increased length of residency (Table 3). Wu and Schimmele [73] and Breslau et al. [74] showed that there is a significant increase in depression and anxiety scores, respectively, whereas no significant changes in scores of both conditions were detected in other studies $[57,58,60]$. When investigating psychological distress among immigrants in Canada, Wang and Palacios [75] found a significant increase over years, whereas Montazer [76] did not detect any significant change. A focus group study by Kaplan et al. [77] revealed an increase in psychological distress among Ghanaian immigrants in the US over years. Participants of this qualitative study linked the rise in their distress levels to various socioeconomic stressors in the destination country (e.g., unequal employment opportunities and loss of social status). Choi et al. [57], on the other hand, reported a significant decrease in distress with increased length of residency among immigrants in the US. Only one study examined mood disorder among immigrants, revealing no significant change over years [74].

\section{Overall MH and Proxy Indicators}

Studies revealed consistent significant evidence for a decline in overall $\mathrm{MH}$ of immigrants with increased length of residency in both North America and Europe (Table 3). Wellbeing was examined in only two European studies and showed significant decline over years [65, 71]. Mexican immigrants reported a decline in their overall $\mathrm{MH}$ and wellbeing with increased length of residency in Canada [78].

\section{Critical Evaluation of the Usage of the HIE Theory in Immigrant MH Studies}

The issues around the usage of the HIE theory were categorized into three categories: (1) conceptual and usage issues, (2) study design issues, and (3) measurement and analysis issues.

\section{Conceptual and Usage Issues}

Across studies, there is a lack of consistency in the conceptual definition of the HIE theory. About $40 \%$ of the studies provide a clear comprehensive definition for the two interrelated HIE and YSIE phenomena, proposing a presence of a $\mathrm{MH}$ advantage among immigrants compared to domestic-born populations that declines with increased length of residency (Table 1). Half of the studies solely focused on the preliminary HIE phenomenon and suggested that immigrants exhibit better $\mathrm{MH}$ than domestic-borns, without 
addressing the complementary YSEI phenomenon that is crucial to understand the trajectory of immigrants' MH outcomes over years. In their cross-sectional studies, $\mathrm{Fu}$ and VanLandingham [79], Breslau et al. [74], and GutierrezVazquez et al. [80] defined the HIE theory as the presence of health advantage among immigrants compared to their nonimmigrant counterparts in the country of origin. Wu et al. [25] and Helgesson et al. [21] presented a more inclusive definition for the HIE theory, suggesting that immigrants have better MH than both domestic-born populations in the receiving country and non-immigrant counterparts in the sending country.

All studies, expect for one study by Yang et al. [61], provided a clear definition for the immigrant study population (Table 1). About $95 \%$ of these studies recruited 1st generation immigrants as the main study population. Perreira et al. [81] and Lee [18], on the other hand, defined their research population as mixed 1 st and 2 nd generation immigrants. The included studies lacked a clear, consistent definition for the comparison group (Table 1). Approximately $67 \%$ of the studies defined the reference group as domestic-born individuals without clarifying whether this comprised $2 \mathrm{nd} / 3 \mathrm{rd}+$ generation immigrants, domestic-born non-immigrants, or combination of both (Table 1). The most common/clear definitions for the comparison group were $2 \mathrm{nd}+$ generation immigrants [24, 82-86] and domestic-born non-immigrants [17, 66, 87-89]. Other clear reference group definitions included $3 r d+$ generation immigrants $[18,63]$ and mixed $3 r d$ generation immigrants and domestic-born non-immigrants [19, 21]. Finally, all of the included research, except for two studies by Kearns et al. [65] and Salas-Wright and Vaughn [64] lacked clarity about the composition of the immigrant group in regard to immigration status (i.e., voluntary immigrants and/or refugees).

\section{Study Design Issues}

Most studies (90\%) employed either a cross-sectional or a secondary analysis design (of cross-sectional data), which is limited by the inability to infer a reliable causality (Table 1 and Online Appendix Table S2). Out of the 26 studies that assessed the YSIE phenomenon (Table 1), only two European studies used a longitudinal design to reliably examine the change in immigrants' $\mathrm{MH}$ with increased length of residency $[21,90]$. In an attempt to obtain insight into the trends of change in immigrants' $\mathrm{MH}$, the other non-longitudinal quantitative studies recruited foreign-born immigrants with different lengths of residency, forming and comparing two groups: recent immigrants and established immigrants. These studies, nonetheless, encountered discrepancies in the definition of both recent and established immigrant groups. While some studies defined recent and established immigrant groups as those with residence of $<10$ years and $\geq 10$ years, respectively $[17,31,34,53,66,71,75,91]$, other studies adopted a higher threshold of $<15$ years and $\geq 15$ years for defining recent and established immigrants, respectively [57, 74, 88]. King et al. [58] and Huang et al. [67], on the other hand, defined recent and established immigrants as those living in North America for $<5$ years and $\geq 5$ years. Dean and Wilson [78], and Kaplan et al. [77] employed a qualitative design to obtain in-depth insight into immigrants' experiences/perspectives of MH status change over time, providing a better understanding of the YSIE phenomenon. To address their aim, Dean and Wilson [78] recruited immigrants of three different length of residencies ( $<3$ years, 3-10 years, and $<10$ years), whereas Kaplan et al. [77] categorized their study participants into four groups $(<5$ years, $5-10$ years, $11-20$ years, and $>20$ years).

Only four studies considered testing the "immigrant selection hypothesis" (i.e., positive selection of healthy immigrants into the receiving country) by recruiting nonimmigrant individuals from the same country of origin as immigrant participants [25, 74, 79, 80]. Two cross-sectional studies of Mexican immigrants in the US considered recruitment of non-immigrants in Mexico to test the selection hypothesis $[74,80]$. Both studies did not include a clear description of either the foreign-born immigrant sample in the US (e.g., established and/or recent immigrants) and the non-immigrant sample in Mexico (e.g., whether intending/ planning for immigration), which would be critical for drawing conclusive evidence about the validity of the immigrant selection hypothesis. Likewise, cross-sectional studies of Vietnamese and Chinese immigrants in the US by Fu and VanLandingham [79], and Wu et al. [25] did not consider a clear description of both immigrant and non-immigrant samples. The lack of an explicit description of immigrant and non-immigrant samples may in part explain the conflicting findings revealed in these four studies, where the immigrant selection hypothesis was supported by Wu et al. [25], yet challenged by Gutierrez-Vazquez et al. [80], Fu and VanLandingham [79], and Breslau et al. [74].

\section{Measurement and Analysis Issues}

Approximately, $19 \%$ of studies relied on perceived questions to examine participants' MH (e.g., self-reporting on subjective mental health), which may have led to different types of bias (recall and /or mis-reporting bias) (Table 1). Approximately $70 \%$ of the studies used data from national statistical agencies and surveys, mainly collected through bio-medically-informed, culturally unadapted tools according to either the Diagnostic and Statistical Manual of Mental Disorders (DSM) or the International Classification of Diseases (ICD). This may have made the data liable to reporting bias. Furthermore, the use of secondary data 
means that the performed analysis is a one-time snapshot of the population in question.

Only about one-quarter of the included studies conducted a sub-ethnic group analysis, which would be useful for assessment of variations in $\mathrm{MH}$ outcomes across different immigrant ethnicities, identifying the most $\mathrm{MH}$ disadvantaged ethnic groups (Table 1). For example, a study by Huang et al. [67] revealed that Western European immigrants are 2.7 times more likely to exhibit depression symptoms relative to Mexican immigrants in the US.; Mexican immigrants, however, had significantly higher depression levels than Asian immigrants in a Canadian study by Ali [53]. Moreover, Latino immigrants showed significantly higher prevalence of substance use disorders than Asian immigrants (19.8 vs. 9.9, respectively) in an American study by Salas-Wright et al. [63]. When performing a sub-ethnic group analysis of $\mathrm{MH}$ among Asian immigrants in the US, Ro and Gee [84] found that the prevalence of poor $\mathrm{MH}$ was highest among Hmong and Cambodian immigrants (23 and $21 \%$, respectively), whereas Japanese and Taiwanese had the lowest prevalence $(3.8 \%$ each).

None of the studies performed an analysis by immigration status, which can be helpful, given the different types of stressors refugees face compared to voluntary immigrants (e.g., exposure to political trauma/torture, suboptimal hygiene in camps and transit countries) that can impact their MH. The impact of age at immigration on immigrants' $\mathrm{MH}$ outcomes was only assessed in three American cross-sectional studies. Salas-Wright et al. [63] reported that those who immigrated to the US as children and adolescents were significantly more likely to meet criteria for substance use disorders than immigrants who came as adults. Likewise, Breslau et al. [74] found that migration at a young age increased the likelihood of exhibiting symptoms of mood disorder among Mexican immigrants in the US. The same patterns were noted for both depression and anxiety among Asian immigrants [35]. Only five studies considered a sub age group analysis to explore variations in immigrants' $\mathrm{MH}$ outcomes across different age groups. Studies by Kwak [66], and Aglipay et al. [91] observed that the $\mathrm{MH}$ advantage among immigrants in Canada is stronger for young adults relative to the elderly. The same patterns were also noted among immigrants in Spain [90]. In contrast, Lee [18] found better $\mathrm{MH}$ outcomes with increased age of immigrants in Australia. Straiton et al. [92] examined interactions between age and gender of immigrants in Australia and noted that aging increased the depression level of women and decreased that of men. Six studies conducted a sub-analysis of gender of immigrants in North America, Europe and Australia and reported a stronger $\mathrm{MH}$ advantage among immigrant males relative to females $[18,31,66,80,90,93]$.

\section{Discussion}

This systematic review critically assessed the use of HIE theory to investigate the presence of $\mathrm{MH}$ advantage among immigrants and the changes in immigrants' MH over time in Western countries. Our review reveals inconsistent evidence regarding the presence of $\mathrm{MH}$ advantage among immigrants compared to domestic-born individuals. While some studies showed significantly better $\mathrm{MH}$ outcomes among immigrants relative to domestic-born comparators supporting the HIE theory, others reported either significantly worse outcomes or non-significant differences. These conflicting findings were also reported in previous HIE-physical health reviews and may in part be explained by inconsistency in definition of reference group [12, 13]. Similar to the included studies in the current review, HIEphysical health research lacks consistency in comparison group definition; definitions varied among 2 nd/3rd + generation immigrants, domestic-born non-immigrants or combination of both [15, 16, 94]. Another potential explanation for the inconsistent findings across HIE studies is the lack of clarity about whether the investigated immigrant group included or excluded refugees. Refugees are more likely than voluntary immigrants to experience multiple stressors throughout their migration trajectory (e.g., political violence, persecution-related trauma, uprooting, suboptimal hygiene) that can affect their health and wellbeing negatively after resettlement [95]. Furthermore, compared to voluntary immigrants, refugees often arrive at the destination country with no or considerably fewer material resources that are necessary for establishing a quality life free from disease and disability. The inconsistency in the findings can, moreover, be explained by the absence of sub-group analysis by racialized status, as racialized immigrants likely encounter more stressors and MH triggers than non-racialized immigrants.

The current study revealed a consistent, convincing evidence for a decline in immigrants' $\mathrm{MH}$ with increased length of residency in the destination country, supporting the YSIE phenomenon. Research showed that immigrants encounter various stressors at different levels in the destination country that continue to accumulate over time, giving rise to a substantial decline in their $\mathrm{MH}$ and wellbeing [35, 96]. For instance, racialized immigrants suffer from racism/harassment in the destination country in various contexts (e.g., street, workplace and schools) [97]. Across leading immigrant-receiving countries, most hate crimes are race and religion-related. For example, xenophobic and religion-related hate crimes in 2018 constituted around $80 \%$ of the entire police-reported hate crimes in each of the US and Canada [98, 99]. The same prevalence was noted for racially/religiously motivated hate crimes 
in Australia in 2016 [100]. Within Western job markets, racial discrimination has been a critical issue, resulting in substantial health andsocial inequities [101]. A recent study of 97 field experiments examining racial discrimination in hiring in North America and Europe reported significant discrimination against non-European immigrants, with the highest racial discrimination rates found in France (85\%), Sweden (65\%), the UK (55\%) and Canada (44\%) [102]. The racially discriminatory job market has become a more critical issue since the start of the coronavirus (COVID-19) pandemic, with immigrants/refugees experiencing substantially higher job losses, increasing their precarity, compared to the domestic-born [103]. A recent Canadian study showed that immigrants are significantly more likely than domestic-born individuals to report that the COVID-19 crisis would have a moderate/major impact on their capability of meeting financial obligations (43 vs. $27 \%$, respectively) [104]. Repeated exposure to these discriminatory behaviors and racial incidents contributes to an increase in distress levels among immigrants, putting their $\mathrm{MH}$ at risk.

Another potential explanation for the noted decline in immigrants' $\mathrm{MH}$ over time is the overmedicalization of $\mathrm{MH}$ challenges in Western countries together with the lack of culturally-sensitive patient-centered health care and culturally competent providers [38]. These factors can be particularly critical for immigrants whose home cultures stigmatize $\mathrm{MH}$ challenges. For example, there has been poor access to MH services among African Americans due to a lack of availability of Black psychotherapists in the US [105]. According to the American Psychological Association, Black psychotherapists represent only about $4 \%$ of the total US psychology workforce [106]. For most African Americans, provision of MH services by a therapist from the same cultural background is critical to facilitate understanding of cultural experiences, particularly those related to racism/ oppression and intergenerational trauma.

Our review showed various issues around the usage of the HIE theory in immigrant MH studies. Half of the studies only focused on the HIE and hypothesized that immigrants demonstrate better MH than domestic-born populations, overlooking the corollary YSIE phenomenon that provides a thorough insight into the trajectory of immigrants' $\mathrm{MH}$ over years in the destination country. This is particularly critical given the various societal stressors/challenges immigrants face which likely result in a decline in their MH [4]. Moreover, many immigrants set optimistic expectations regarding their lives following immigration (e.g., better job opportunities in their field of expertise) that are not met despite continuous attempts, causing a sense of personal failure mixed with disappointment at the discriminatory system in the destination country [107]. For example, research has showed that although most immigrants to Canada are selected according to a strict, skill-based point system, many are not accepted in job opportunities related to their education/training, due to a discriminatory barrier- the lack of the so-called "Canadian experience" [108].

Most of the HIE-MH studies (90\%) included in this systematic review employed either a cross-sectional or secondary analysis (of cross-sectional data) design, underscoring the paucity of well-grounded longitudinal and qualitative research. Besides helping to interpret quantitative research findings, qualitative studies would give a deeper insight into immigrants' perceptions and experiences of $\mathrm{MH}$ status [78]. The included studies relied on bio-medically-informed, culturally unadapted tools mainly according to the DSM; this practice has heavily been criticized by scholars due to underrecognizing individuals' lived negative experiences emanating from social inequities [39]. Most studies (75\%) did not conduct a sub-ethnic group analysis, which is crucial given that some ethnic groups, particularly racialized ones, likely face significantly higher stressors that put their MH more at risk compared to non-racialized groups. Furthermore, every ethnic group could have their own lived experiences and unique challenges that impact their MH. For example, a Canadian cross-sectional study revealed that the Chinese community has disproportionately faced discrimination and psychological distress since the start of the COVID-19 pandemic because the virus was first detected in China [109].

\section{Strengths and Limitations}

The current systematic review comprehensively addressed the applicability of the HIE theory to MH of immigrants in Western countries, an under-researched area in immigrant MH research. This review also provided a critical assessment of the use of the HIE theory in immigrant MH studies to inform potential modification/improvement. A rigorous systematic search strategy was adopted, searching five electronic databases of health and social sciences. A retrospective registration of this review was made in PROSPERO to enhance transparency and reduce reporting bias. One limitation of this review is that only English papers were eligible, posing a likelihood of excluding potential non-English articles from continental Europe. As well, a limited segment of the migration phenomenon was captured in this study given that there are many immigrant/refugee-receiving countries that lack resources to conduct HIE-MH research (e.g., Palestinian refugees dispersed across the Middle East, Venezuelan immigrants in Central and South America). Most of the synthesized evidence in this study came from cross-sectional studies, which are associated with limited ability to make reliable causal inferences [35]. Nearly all the included studies used either perceived MH questions or self-reported $\mathrm{MH}$ scales, making the review's findings liable to recall and /or mis-reporting bias stemming from MH stigma [110]. 


\section{Conclusions and Future Directions}

HIE-MH research appears to be limited and is primarily restricted to cross-sectional and secondary analysis studies, highlighting the paucity of longitudinal and qualitative research in this field. North America and Europe are relatively ahead of Australia in HIE-MH research, whereas New Zealand apparently lacks this type of research. Inconsistent evidence was revealed regarding the presence of $\mathrm{MH}$ advantage among immigrants compared to domesticborn individuals, questioning the applicability of HIE theory to MH. Most HIE-MH research provided a clear consistent definition for the immigrant group, whereas the comparison group definition lacked clarity and consistency across studies. Consistent, convincing evidence was found for a decline in $\mathrm{MH}$ of immigrants with increased length of residency in the destination country, supporting the YSIE phenomenon.

Regarding future research, mixed-method and qualitative study designs are recommended to provide in-depth and comprehensive insight into immigrants' MH experiences in the destination country and the trends in changes in MH outcomes with increased length of residency. This would help determine potential MH determinants and protective factors/resources (e.g., social/community cohesion, translated resources, culturally-relevant activities), informing the development of effective and tailored, $\mathrm{MH}-$ promoting interventions/programs that best serve immigrants' needs. Sub-group analyses by potentially important factors, such as age, gender, age at migration, immigration status, racialized status, and ethnicity, is required to identify variations in $\mathrm{MH}$ outcomes across different subgroups. In terms of the assessment of $\mathrm{MH}$, the use of a combination of both perceived $\mathrm{MH}$ questionnaires and objective scales that are culturally sensitive is recommended to improve data reliability and validity.

Concerning theoretical frameworks, although the use of HIE theory in immigrant health research can help reveal MH disparities, this theory alone does not explain how and why these disparities exist nor inform about potential ways to improve immigrants' MH. This highlights the need for a paradigm shift from the sole use of the HIE theory to incorporating other potential theoretical concepts and frameworks to help understand the whole picture regarding the reasons for disparities and the decline in immigrants' MH over years. Alongside the HIE theory, the "Health Inequalities Action" framework can be helpful in providing insight into the reasons behind $\mathrm{MH}$ inequities and propose viable solutions to enhance immigrants' $\mathrm{MH}$ [111]. This framework is developed by the Glasgow Centre for Population Health and the National Health Service for addressing health inequalities and developing equity promotion strategies for community health and social care services. The framework starts with understanding the needs/lived experiences of marginalized populations, including immigrants/refugees, and comparing their health outcomes to the broader population. This is followed by developing community-informed interventions that help address the reported needs, reducing the inequity gap. Finally, the concept of resilience can be beneficial to explore potential resources that can help immigrants adapt/cope in face of adversities and to inform the design of effective interventions.

Supplementary Information The online version contains supplementary material available at https://doi.org/10.1007/s10903-021-01313-5.

Acknowledgements SE was funded by the Social Sciences and Humanities Research Council of Canada during this work.

Data Availability All relevant data are included within this manuscript and its supplementary information files.

\section{References}

1. United Nations. Transforming our world: The 2030 Agenda for Sustainable Development. 2015. https://www.un.org/ga/search/ view_doc.asp?symbol=A/RES/70/1\&Lang=E. Accessed 11 June 2020

2. Ryan G, Qureshi O, Salaria N, Eaton J. Mental health and the 2030 Sustainable Development Agenda: Global inaction on mental health is putting the brakes on development. 2018 . https://globalmentalhealthcommission.org/wp-content/uploa ds/2018/10/UNGA_policy-brief_MHIN1.pdf.pdf. Accessed 12 June 2020

3. GHDx. GBD results tool. 2019. http://ghdx.healthdata.org/gbdresults-tool. Accessed 13 June 2020.

4. Elshahat S, Moffat T. Mental health triggers and protective factors among Arabic-speaking immigrants and refugees in North America: a scoping review. J Immigr Minor Health. 2021. https://doi.org/10.1007/s10903-021-01215-6.

5. United Nations. Trends in international migration. 2015. https://www.un.org/en/development/desa/population/migra tion/publications/populationfacts/docs/MigrationPopFacts201 54.pdf. Accessed 27 June 2020.

6. United Nations. The number of international migrants reaches 272 million, continuing an upward trend in all world regions, says UN. 2019. https://www.un.org/development/desa/en/news/ population/international-migrant-stock-2019.html. Accessed 27 June 2020.

7. Australian Bureau of Statistics. Australia's population: Over 7.5 million born overseas. 2020. https://www.abs.gov.au/ ausstats/abs@.nsf/mediareleasesbytitle/35A203AB6DD3CA0 BCA257600002314F7?OpenDocument\#: :text=In\%20the\% 20year\%20to\%2030,cent\%20who\%20were\%20international\% 20students. Accessed 27 June 2020.

8. Statistics Canada. Focus on geography series, 2016 census. 2019. https://www12.statcan.gc.ca/census-recensement/2016/ as-sa/fogs-spg/Facts-can-eng.cfm?Lang=Eng\&GK=CAN\& $\mathrm{GC}=01 \& \mathrm{TOPIC}=7$. Accessed 12 June 2020 . 
9. United Nations. International migrant stock 2019. 2019. https:// www.un.org/en/development/desa/population/migration/data/ estimates2/estimates19.asp. Accessed 28 June 2020.

10. Newbold B. Chronic conditions and the healthy immigrant effect: evidence from Canadian immigrants. J Ethn Migr Stud. 2006;32:765-84.

11. Aldridge RW, Nellums LB, Bartlett S, Barr AL, Patel P, Burns $\mathrm{R}$, et al. Global patterns of mortality in international migrants: a systematic review and meta-analysis. Lancet. 2018;392:2553-66.

12. Vang ZM, Sigouin J, Flenon A, Gagnon A. Are immigrants healthier than native-born Canadians? A systematic review of the healthy immigrant effect in Canada. Ethn Health. 2017;22:209-41.

13. Jin K, Ding D, Gullick J, Koo F, Neubeck L. A Chinese immigrant paradox? Low coronary heart disease incidence but higher short-term mortality in Western-dwelling Chinese immigrants: a systematic review and meta-analysis. J Am Heart Assoc. 2015;4:e02568.

14. $\mathrm{Ng} \mathrm{E}$, Zhang $\mathrm{H}$. The mental health of immigrants and refugees: Canadian evidence from a nationally linked database. Health Rep. 2020;31:3-12.

15. Osypuk TL, Alonso A, Bates LM. Understanding the healthy immigrant effect and cardiovascular disease: looking to big data and beyond. Circulation. 2015;132:1522-4.

16. Hamilton TG. The healthy immigrant (migrant) effect: in search of a better native-born comparison group. Soc Sci Res. 2015;54:353-65.

17. Kwak K. An evaluation of the healthy immigrant effect with adolescents in Canada: examinations of gender and length of residence. Soc Sci Med. 2016;157:87-95.

18. Lee R. Does the healthy immigrant effect apply to mental health? Examining the effects of immigrant generation and racial and ethnic background among Australian adults. SSM Popul Health. 2019;7:100311.

19. Van Geel M, Vedder P. The adaptation of non-Western and Muslim immigrant adolescents in the Netherlands: an immigrant paradox? Scand J Psychol. 2010. https://doi.org/10.1111/j.14679450.2010.00831.x.

20. Bousmah M-Q, Combes J-BS, Abu-Zaineh M. Health differentials between citizens and immigrants in Europe: a heterogeneous convergence. Health Policy. 2019;123:235-43.

21. Helgesson M, Johansson B, Nordquist T, Vingård E, Svartengren M. Healthy migrant effect in the Swedish context: a registerbased, longitudinal cohort study. BMJ Open. 2019;9:e026972.

22. Bostean G. Does selective migration explain the Hispanic paradox? A comparative analysis of Mexicans in the U.S. and Mexico. J Immigr Minor Health. 2012;15:624.

23. Ramraj C, Pulver A, Siddiqi A. Intergenerational transmission of the healthy immigrant effect (HIE) through birth weight: a systematic review and meta-analysis. Soc Sci Med. 2015;146:29-40.

24. Oh H, Abe J, Negi N, DeVylder J. Immigration and psychotic experiences in the United States: another example of the epidemiological paradox? Psychiatry Res. 2015;229:784-90.

25. Wu B, Chi I, Plassman B, Guo M. Depressive symptoms and health problems among Chinese immigrant elders in the US and Chinese elders in China. Aging Ment Health. 2010;14:695-704.

26. Mendenhall E, Kim AW. Rethinking idioms of distress and resilience in anthropology and global mental health. In: Dyer AR, Kohrt BA, Candilis PJ, editors. Global mental health ethics. Cham: Springer; 2021. p. 157-70.

27. Ungar M. Resilience, trauma, context, and culture. Trauma Violence Abus. 2013;14:255-66.

28. Panter-Brick C. Health, risk, and resilience: interdisciplinary concepts and applications. Annu Rev Anthropol. 2014;43:431-48.

29. Windle G. What is resilience? A review and concept analysis. Rev Clin Gerontol. 2011;21:152-69.
30. McDonald JT, Kennedy S. Insights into the 'healthy immigrant effect': health status and health service use of immigrants to Canada. Soc Sci Med. 2004;59:1613-27.

31. Lou Y, Beaujot R. What happens to the 'healthy immigrant effect': the mental health of immigrants to Canada. PSC Discuss Pap Ser. 2005;19:1.

32. Wang M, Beal DJ, Chan D, Newman DA, Vancouver JB, Vandenberg RJ. Longitudinal research: a panel discussion on conceptual issues, research Design, and statistical techniques. Work Aging Retire. 2016;3:1-24.

33. Newbold B, Simone D. Comparing disability amongst immigrants and native-born in Canada. Soc Sci Med. 2015;145:53.

34. Stafford M, Newbold BK, Ross NA. Psychological distress among immigrants and visible minorities in Canada: a contextual analysis. Int J Soc Psychiatry. 2010;57:428-41.

35. Lau A, Tsai W, Shih J, Liu L, Chin-Wei H, Takeuchi D. The immigrant paradox among Asian American women: are disparities in the burden of depression and anxiety paradoxical or explicable? J Consult Clin Psychol. 2013;81:901.

36. Bhatnagar J. Multicultural education in a psychological perspective. In: Husén T, Opper S, editors. Multicultural and Multilingual Education in Immigrant Countries: Proceedings of an International Symposium Held at the Wenner-Gren Center, Stockholm, August 2 and 3, 1982. Elsevier; 2014. p. 59-77.

37. Tuggle A, Cohen J, Crews D. Stress, migration, and allostatic load: a model based on Mexican migrants in Columbus. Ohio J Physiol Anthropol. 2018;37:28.

38. Kleinman A. Medical anthropology and mental health: five questions for the next fifty years. In: Inhorn MC, Wentzell EA, editors. Medical anthropology at the intersections: histories, activisms, and futures. London: Duke University Press; 2012.

39. Kleinman A, Benson P. Anthropology in the clinic: the problem of cultural competency and how to fix It. PLOS Med. 2006;3:e294.

40. Anglin D, Lighty Q, Yang L, Barrett M, Miles R, Slonim $\mathrm{T}$, et al. Discrimination, arrest history, and major depressive disorder in the U.S. Black population. Psychiatry Res. 2014;219:114.

41. Millett LS. The Healthy immigrant paradox and child maltreatment: a systematic review. J Immigr Minor Health. 2016;18:1199-215.

42. Jawetz T. Restoring the rule of law through a fair, humane, and workable immigration system. 2019. https://www.americanpr ogress.org/issues/immigration/reports/2019/07/22/472378/ restoring-rule-law-fair-humane-workable-immigration-system/. Accessed 21 July 2020.

43. Wood LCN. Impact of punitive immigration policies, parentchild separation and child detention on the mental health and development of children. BMJ Paediatr Open. 2018;2:e000338.

44. Islam F. Examining the "healthy immigrant effect" for mental health in Canada. Univ Toronto Med J. 2013;90:169-75.

45. Moher D, Shamseer L, Clarke M, Ghersi D, Liberati A, Petticrew M, et al. Preferred reporting items for systematic review and meta-analysis protocols (PRISMA-P) 2015 statement. Syst Rev. 2015;4:1-9.

46. CEBM. Critical appraisal. 2019. https://www.cebma.org/resou rces-and-tools/what-is-critical-appraisal/. Accessed 17 Aug 2020.

47. Haberer J, Trabin T, Klinkman M. Furthering the reliable and valid measurement of mental health screening, diagnoses, treatment and outcomes through health information technology. Gen Hosp Psychiatry. 2013;35:349.

48. Hilland TA, Bourke M, Wiesner G, Garcia Bengoechea E, Parker AG, Pascoe M, et al. Correlates of walking among disadvantaged groups: a systematic review. Health Place. 2020;63:102337. 
49. Sallis JF, Prochaska JJ, Taylor WC. A review of correlates of physical activity of children and adolescents. Med Sci Sports Exerc. 2000;32:963-75.

50. Zhang R, Wulff H, Duan Y, Wagner P. Associations between the physical environment and park-based physical activity: a systematic review. J Sport Heal Sci. 2018;8:412.

51. Fincham J. Response rates and responsiveness for surveys, standards. Am J Pharm Educ. 2008;72:43.

52. Budhwani H, Hearld KR, Chavez-Yenter D. Depression in racial and ethnic minorities: the impact of nativity and discrimination. J Racial Ethn Heal Disparities. 2015;2:34-42.

53. Ali J. Mental health of Canada's immigrants. 2002. https:// www150.statcan.gc.ca/n1/en/catalogue/82-003-S200200163 36. Accessed 12 Aug 2020.

54. Boen CE, Hummer RA. Longer-but harder-lives? The Hispanic health paradox and the social determinants of racial, ethnic, and immigrant-Native health disparities from midlife through late life. J Health Soc Behav. 2019;60:434-52.

55. Casillas A, Leng M, Liu K, Hernandez A, Shrager S, Kanaya A. A long way from home: comparing mental health measures between foreign and U.S.-born Latinos in the Multi-Ethnic Study of Atherosclerosis (MESA). J Health Care Poor Underserved. 2012;23:1719-32.

56. Silveira E, Skoog I, Sundh V, Allebeck P, Steen B. Health and well-being among 70-year-old migrants living in Swedenresults from the $\mathrm{H} 70$ gerontological and geriatric population studies in Göteborg. Soc Psychiatry Psychiatr Epidemiol. 2002;37:13-22.

57. Choi S, Kim G, Lee S. Effects of nativity, length of residence, and county-level foreign-born density on mental health among older adults in the U.S. Psychiatr Q. 2016;87:675.

58. King L, Feeley N, Gold I, Hayton B, Zelkowitz P. The healthy migrant effect and predictors of perinatal depression. Women Birth. 2019;32:e341-50.

59. Menezes NM, Georgiades K, Boyle MH. The influence of immigrant status and concentration on psychiatric disorder in Canada: a multi-level analysis. Psychol Med. 2011;41:2221-31.

60. John DA, de Castro AB, Martin DP, Duran B, Takeuchi DT. Does an immigrant health paradox exist among Asian Americans? Associations of nativity and occupational class with self-rated health and mental disorders. Soc Sci Med. 2012;75:2085-98.

61. Yang W, Qeadan F, Smith-Gagen J. The Hispanic epidemiological paradox in the fastest-growing state in the United States. Hisp Heal Care Int. 2009;7:130-40.

62. Salas-Wright CP, Kagotho N, Vaughn MG. Mood, anxiety, and personality disorders among first and second-generation immigrants to the United States. Psychiatry Res. 2014;220:1028-36.

63. Salas-Wright C, Vaughn M, Clark T, Terzis L, Cordova D. Substance use disorders among first- and second-generation immigrant adults in the United States: evidence of an immigrant paradox? J Stud Alcohol Drugs. 2014;75:958-67.

64. Salas-Wright C, Vaughn M. A "refugee paradox" for substance use disorders? Drug Alcohol Depend. 2014;142:345.

65. Kearns A, Whitley E, Egan M, Tabbner C, Tannahill C. Healthy migrants in an unhealthy city? The effects of time on the health of migrants living in deprived areas of Glasgow. J Int Migr Integr. 2017;18:675-98.

66. Kwak K. Age and gender variations in healthy immigrant effect: a population study of immigrant well-being in Canada. J Int Migr Integr. 2018;19:413-37.

67. Huang C, Mehta NK, Elo IT, Cunningham SA, Stephenson $\mathrm{R}$, Williamson DF, et al. Region of birth and disability among recent U.S. immigrants: evidence from the 2000 census. Popul Res Policy Rev. 2011;30:399-418.

68. Davison KM, Gondara L. A Comparison of mental health, food insecurity, and diet quality indicators between foreign-born immigrants of Canada and native-born Canadians. J Hunger Environ Nutr. 2019;16:109.

69. Gotsens M, Malmusi D, Villarroel-Williams N, Vive-Cases C, Garcia I, Hernando C, et al. Health inequality between immigrants and natives in Spain: the loss of the healthy immigrant effect in times of economic crisis. Eur J Public Health. 2015;25:923.

70. Farley T, Galves A, Dickinson LM, de Perez MJD. Stress, coping, and health: a comparison of Mexican immigrants, Mexican-Americans, and non-Hispanic whites. J Immigr Health. 2005;7:213-20.

71. Rivera B, Casal B, Currais L. The healthy immigrant effect on mental health: determinants and implications for mental health policy in Spain. Adm Policy Ment Heal Ment Heal Serv Res. 2016;43:616-27.

72. Calvo R, Carr DC, Matz-Costa C. Another paradox? The life satisfaction of older Hispanic immigrants in the United States. J Aging Health. 2016;29:3-24.

73. Wu Z, Schimmele CM. The healthy migrant effect on depression: variation over time? Can Stud Popul. 2005;32:271.

74. Breslau J, Aguilar-Gaxiola S, Borges G, Castilla-Puentes R, Kendler K, Medina-Mora M, et al. Mental disorders among English-speaking Mexican immigrants to the US compared to a national sample of Mexicans. Psychiatry Res. 2007;151:115-22.

75. Wang L, Palacios E. The social and spatial patterning of life stress among immigrants in Canada. J Immigr Minor Health. 2017;19:665.

76. Montazer S. Disentangling the effects of primary and secondary international migration on psychological distress: the role of mastery. Can J Public Health. 2018;109:284-93.

77. Kaplan SA, Ahmed R, Musah A. "When you walk in the rain, you get wet": a qualitative study of Ghanaian immigrants' perspective on the epidemiological paradox. J Immigr Minor Health. 2015;17:255-62.

78. Dean JA, Wilson K. "My health has improved because I always have everything I need here...": a qualitative exploration of health improvement and decline among immigrants. Soc Sci Med. 2010;70:1219-28.

79. Fu H, VanLandingham MJ. Mental health consequences of international migration for Vietnamese Americans and the mediating effects of physical health and social networks: results from a natural experiment approach. Demography. 2012;49:393-424.

80. Gutierrez-Vazquez E, Flippen C, Parrado E. Migration and depression: a cross-national comparison of Mexicans in sending communities and Durham, NC. Soc Sci Med. 2018;219:1-10.

81. Perreira K, Marchante A, Schwartz S, Isasi C, Carnethon M, Corliss H, et al. Stress and resilience: key correlates of mental health and substance use in the Hispanic community health study of Latino youth. J Immigr Minor Health. 2018;21:4.

82. Bowe AG. The immigrant paradox on internalizing symptoms among immigrant adolescents. J Adolesc. 2017;55:72-6.

83. Moreno O, Cardemil E. The role of religious attendance on mental health among Mexican populations: a contribution toward the discussion of the immigrant health paradox. Am J Orthopsychiatry. 2016;88:10.

84. Ro A, Gee GC. Disability status differentials among Asian immigrants in the United States: the added dimensions of duration and age. Race Soc Probl. 2012;4:83-92.

85. Tummala-Narra P, Claudius M. Perceived discrimination and depressive symptoms among immigrant-origin adolescents. Cult Divers Ethn Minor Psychol. 2013;19:257-69.

86. Viruell-Fuentes E, Andrade F. Testing immigrant social ties explanations for Latino health paradoxes: the case of social support and depression symptoms. J Latino/Latin Am Stud. 2016;8:77-92. 
87. Kwak K, Rudmin F. Adolescent health and adaptation in Canada: examination of gender and age aspects of the healthy immigrant effect. Int J Equity Health. 2014;13:103.

88. Schutt RK, Nayak MM, Creighton M. The healthy immigrant effect: a test of competing explanations in a low income population. Heal Sociol Rev. 2019;28:1-19.

89. Urquia ML, O'Campo PJ, Heaman MI. Revisiting the immigrant paradox in reproductive health: the roles of duration of residence and ethnicity. Soc Sci Med. 2012;74:1610-21.

90. Ronda-Pérez E, Martínez J, Reid A, Agudelo-Suárez A. Longer residence of Ecuadorian and Colombian migrant workers in Spain associated with new episodes of common mental disorders. Int J Environ Res Public Health. 2019;16:2027.

91. Aglipay M, Colman I, Chen Y. Does the healthy immigrant effect extend to anxiety disorders? Evidence from a nationally representative study. J Immigr Minor Health. 2013;15:851-7.

92. Straiton M, Grant JF, Winefield HR, Taylor A. Mental health in immigrant men and women in Australia: the North West Adelaide health study. BMC Public Health. 2014;14:1111.

93. Henares-Montiel J, Ruiz-Perez I, Mendoza-Garcia O. Health inequalities between male and female immigrants in Spain after the beginning of the economic crisis. Health Soc Care Community. 2018;26:891-7.

94. Teruya SA, Bazargan-Hejazi S. The immigrant and Hispanic paradoxes: a systematic review of their predictions and effects. Hisp J Behav. 2013;35:486-509.

95. Daynes L. The health impacts of the refugee crisis: a medical charity perspective. Clin Med (Northfield Il). 2016;16:437-40.

96. Eldeeb SY. Understanding and addressing Arab-American mental health disparities. Sch Undergrad Res J Clark. 2017;3:1.

97. Aranda E, Vaquera E. Racism, the immigration enforcement regime, and the implications for racial inequality in the lives of undocumented young adults. Sociol Race Ethn. 2015;1:88-104.

98. USDOJ. FBI releases 2018 hate crime statistics. 2020. https:// www.justice.gov/hatecrimes/hate-crime-statistics. Accesssed 29 July 2020 .

99. Statistics Canada. Police-reported hate crime, by type of motivation, Canada (selected police services). 2020. https://www150. statcan.gc.ca/t1/tbl1/en/tv.action?pid=3510006601. Accessed 29 July 2020.

100. Mason G. A picture of bias crime in New South Wales. Cosmop Civil Soc Interdiscip J. 2019;11:47-66.

101. Borowczyk-Martins D, Bradley J, Tarasonis L. Racial discrimination in the U.S. labor market: employment and wage differentials by skill. Labour Econ. 2017;49:106-27.

102. Quillian L, Heath A, Pager D, Midtbøen AH, Hexel F, Fleischmann O. Do some countries discriminate more than others? Evidence from 97 field experiments of racial discrimination in hiring. Sociol Sci. 2019;6:467.

103. LaRochelle-Côté S, Uppal S. The social and economic concerns of immigrants during the COVID-19 pandemic. 2020. https:// www150.statcan.gc.ca/n1/pub/45-28-0001/2020001/article/ 00012-eng.htm. Accessed 3 July 2020.

104. Charles $\mathrm{CH}$. Immigrants are worrying about social ties and finances during coronavirus. 2020. https://theconversation.com/ immigrants-are-worrying-about-social-ties-and-finances-duringcoronavirus-137983?utm_medium=email\&utm_campaign=Latest\%20from. Accessed 20 Aug 2020.

105. Ward E, Wiltshire J, Detry M, Brown R. African American men and women's attitude toward mental illness, perceptions of stigma, and preferred coping behaviors. Nurs Res. 2013;62:185.

106. Lin L, Stamm K, Christidis P. How diverse is the psychology workforce? Cent Work Stud. 2018;49:19.

107. George U, Thomson MS, Chaze F, Guruge S. Immigrant mental health, a public health issue: looking back and moving forward. Int J Environ Res Public Health. 2015;12:13624-48.

108. Ontario Human Rights Commission. Talking about Canadian experience. 2019. http://www.ohrc.on.ca/en/talking-about-canad ian-experience-fact-sheet. Accessed 29 Sept 2021.

109. Zhang W, Chai L, Fan J, Wang P, Wei X, Yang L. COVID-19, racial discrimination, and psychological distress. Ann Epidemiol. 2020;52:106.

110. Brown S, Harris MN, Srivastava P, Taylor K. Mental health and reporting bias: analysis of the GHQ - 12. Sheff Econ Res Pap Ser. 2018;201801.

111. Craig P. Health inequalities action framework. 2013. http://www. healthscotland.scot/media/1223/health-inequalities-action-frame work_june13_english.pdf. Accessed 23 May 2021.

112. Abdul-Malak Y. Healthy immigrants? Exploring depressive symptoms among Caribbean and Mexican immigrants. J Racial Ethn Health Disparities. 2020;7:488-97.

113. Alegria M, Canino G, Shrout P, Woo M, Duan N, Vila D, et al. Prevalence of mental illness in immigrant and non-immigrant U.S. Latino groups. Am J Psychiatry. 2008;165:359-69.

114. Claassen K, Broding $\mathrm{H}$. Mental strain of immigrants in the working context. Int J Environ Res Public Health. 2019;16:2875.

115. Dhadda A, Greene G. "The healthy migrant effect" for mental health in England: propensity-score matched analysis using the EMPIRIC survey. J Immigr Minor Health. 2017;20:799.

116. Katsiaficas D, Suárez-Orozco C, Sirin S, Gupta T. Mediators of the relationship between acculturative stress and internalization symptoms for immigrant origin youth. Cult Divers Ethnic Minor Psychol. 2013;19:27-37.

117. Santos-Lozada A. Self-rated mental health and race/ethnicity in the United States: support for the epidemiological paradox. PeerJ. 2016;4:e2508.

Publisher's Note Springer Nature remains neutral with regard to jurisdictional claims in published maps and institutional affiliations. 